\title{
Testing of a road structure for frost resistance using the curve of frost heaving intensity
}

\author{
$G L \mathrm{Kagan}^{1}, V A$ Shorin $^{1}$, and $A Y$ Velsovskij ${ }^{1, *}$ \\ ${ }^{1}$ Department of Highways, Vologda State University, Lenina str. 15, 160000, Russia
}

\begin{abstract}
The article considers the main provisions of the regulatory methodology for estimation the frost resistance of a road structure. The technique for determining the degree of soil heaving is assessed taking into that the standard for its determination was issued in 1990. The intensity of frost heaving and its curve are being discussed. The characteristic curve of frost heaving intensity is substantiated in relation to road structures. The possibility of its plotting according to laboratory tests is being considered. A new method for testing of a road structure for frost resistance is proposed, the essence of which is illustrated by an example.
\end{abstract}

\section{Introduction}

The basis of the regulatory methodology for testing of a road structure for frost resistance is the limitation of heaving deformation of a road surface. It consists in the fulfillment of the following inequality: the calculated soil heaving of a subgrade $\left(l_{h}\right)$ should not exceed soil heaving, which is acceptable for this construction $\left(l_{\mathrm{acc}}\right)$, that is, $1_{\mathrm{h}} \leq 1_{\text {acc }}$.

The current standards [1] include the methodology for determining $l_{h}$ and $l_{\text {acc }}$ depending on the type of pavement and enveloping.

The standard method for determining $l_{h}$ was developed by the Russian scientists in the 70s of the last century. The theoretical basis for it was the solution of N.A. Puzakov, which was brought to practical implementation by a team of employees of the USSR Leningrad Road Research Institute (LenSoyuzDORNII) under the leadership of M.B. Korsunsky. Up to the present moment, this technique has not undergone significant changes.

One of the main characteristics of soil for this technique is the soil group according to the heaving degree. At the time when the normative method was issued, there was no standard for determining the degree of heaving, and the authors included methods for determining this characteristic in the method. These methods included both usage of laboratory equipment, and relationships, allowing one to determine the desired characteristic using the soil physical properties. Considering that these methods give only an approximate value of heaving, the influence of a number of natural factors was taken into account by introducing the corresponding coefficients. In 1990, the first standard for laboratory tests to determine the degree of soil heaving was issued [2]. It is determined using the relative deformation of frost heaving $\left(\varepsilon_{\mathrm{fn}}\right)$ obtained from the expression: $\varepsilon_{\mathrm{fn}}=\mathrm{h}_{\mathrm{f}} / \mathrm{Z}_{\mathrm{i}}$, where $\mathrm{h}_{\mathrm{f}}$ is the vertical deformation of a soil sample at the end of test when the sample freezes to a depth of $\mathrm{z}_{\mathrm{i}}$.

The authors of the standard note that the results of laboratory tests make it possible to determine the complete deformation of soil in field conditions with an accuracy of $10-15 \%$.

In engineering practice, in addition to $\varepsilon_{\mathrm{fn}}$, a curve of frost heaving intensity is used to determine the deformation of frost heaving of soil. The intensity of frost heaving (f) is defined at any point of a soil mass (Fig. 1), as the ratio of the increment of frost heaving $\left(\mathrm{dl}_{\mathrm{h}}\right)$ to the increment of freezing depth $(\mathrm{dz})$, that is, $\mathrm{f}=$ $\mathrm{dl}_{\mathrm{h}} / \mathrm{dz}$.

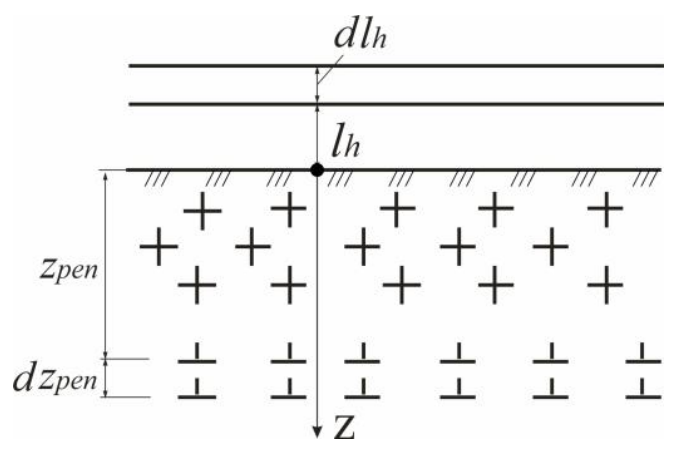

Fig. 1. The scheme of freezing of a soil mass.

\footnotetext{
* Corresponding author: v2u@yandex.ru
} 


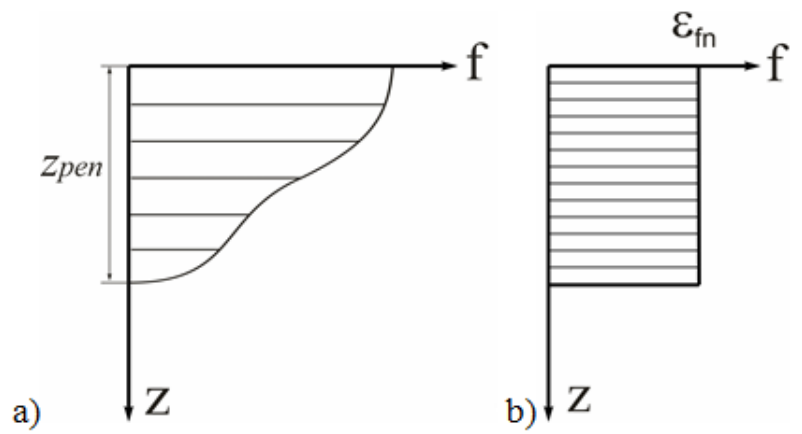

Fig. 2. The curves of frost heaving intensity a) General form; b) At a constant intensity equal to $\varepsilon_{\mathrm{fn}}$.

A general form of the intensity of frost heaving is shown in Figure 2a. Obviously, its area is equal to the total deformation of heaving of the frozen soil mass. The definition of $\varepsilon_{\mathrm{fn}}$ shows that its value represents the average intensity of frost heaving. A general form of this curve is shown in Figure 2b. Thus, the presence of a curve of intensity of frost heaving in relation to road construction ensures that they are tested for frost resistance. Hence, of interest is a set of long-term field experimental studies in this area carried out at the Igarskaya (Western Siberia) and Skovorodinskaya (Transbaikalia) permafrost stations, headed by V.O. Orlov. The results of these studies are presented in [3].

In this work, characteristic curves for two cases are identified depending on the distribution of pre-winter moisture in soil (W) over the depth of freezing (Zpen) and the occurrence of groundwater.

The first case corresponds to a close occurrence of groundwater to the freezing boundary, and the second case corresponds to their deep occurrence. Corresponding plots of distribution of humidity (W) and frost heaving intensity (f) are given in Figure 3a for the first case, and in Figure $3 \mathrm{~b}$ for the second case.

Note that as applied to a road structure, the first case corresponds to lowered sections of relief with a high occurence of groundwater. Such road sections are usually referred to as heaving-prone. The second case is typical for flat sections with the road construction in an embankment when the groundwater horizon is located at a depth of more than 1.5 meters from the surface. This case is the most frequent for the practice of road construction.

The triangular nature of variation of intensity curve along the freezing depth was also discovered during experimental field studies at a number of objects carried out by the scientists of the Central Research, Experimental and Design Institute for Rural Construction (CNIIEPSelstroy Institute) [4].

As applied to a road structure, a similar character of curve of frost heaving intensity can be taken as the main one.

As was noted earlier, for a rectangular curve of frost heaving intensity, the laboratory tests make it possible to determine the deformation of frost heaving during freezing with the necessary accuracy. Obviously, the areas of the rectangular curve (Figure 4a) and the triangular curve (Figure $4 \mathrm{~b}$ ) should be equal: $Z_{\text {pen }} \cdot \varepsilon_{\mathrm{fn}}$ $=1 / 2 f_{\text {max }} \cdot Z_{\text {pen, }}$ whence $f_{\max }=2 \cdot \varepsilon_{\text {fn }}$.

Therefore, based on laboratory test data, it is possible to construct a triangular curve of frost heaving intensity, which corresponds to the nature of its distribution in the field conditions.

The presence of this curve makes it possible to test the road structure for frost resistance and determine the thickness of frost protection layer. The sequence of necessary calculations will be shown by an example.

It is required to determine the thickness of frost protection layer for a section of the planned road of the III technical category near Vologda. The initial data necessary to perform this calculation include:

- The thickness of pavement, determined by the strength condition $Z_{\text {pen(pr) }}=45 \mathrm{~cm}$. This construction is made of non-heaving materials;

- The relative deformation of frost heaving of soil subgrade, determined from laboratory tests $\varepsilon_{\mathrm{fn}}=0.077$;

- The acceptable deformation of frost heaving for this road $l_{\mathrm{acc}}=4 \mathrm{~cm}$;

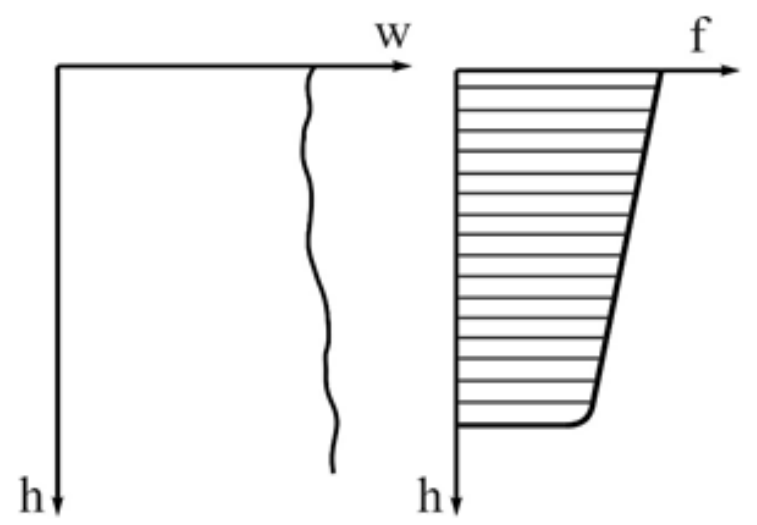

a

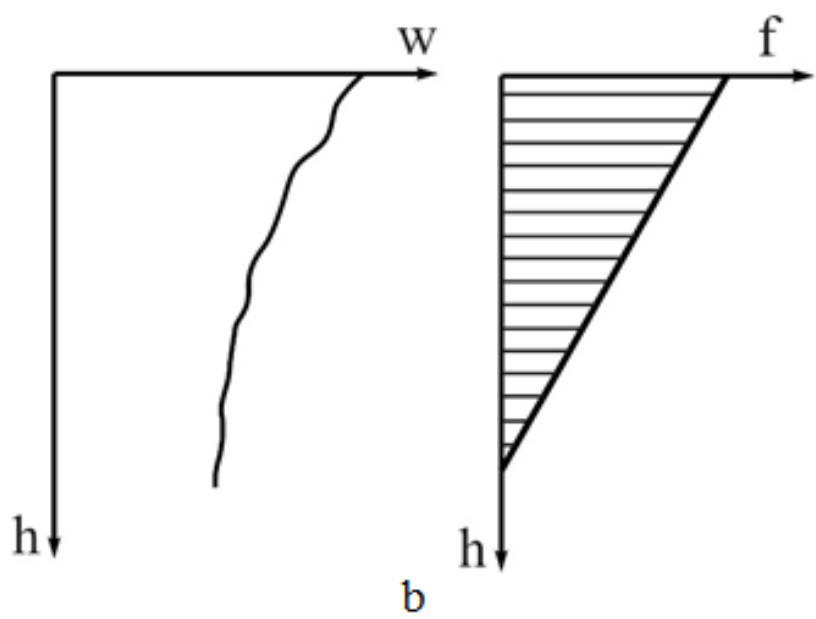

Fig. 3. Characteristic curves of pre-winter humitidy and frost heaving intensity: a - for a close occurrence of groundwater to the freezing soil, $\mathrm{b}$ - for a deep occurrence of groundwater to the freezing soil. 


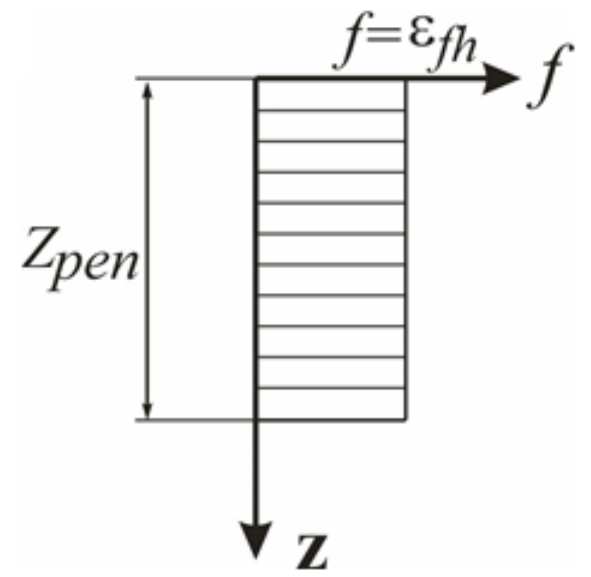

a)

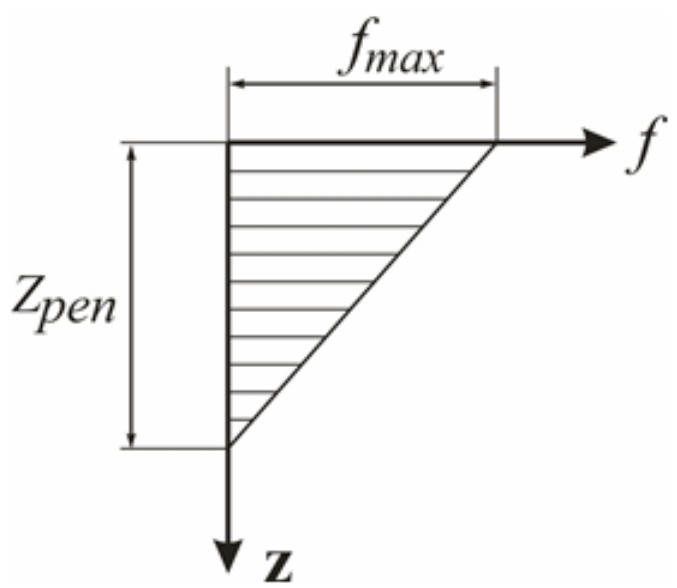

b)

Fig. 4. Calculated curves of frost heaving intensity.

- The calculated freezing depth $Z_{\text {pen }}=207 \mathrm{~cm}$.

The calculation is performed in the following order:

1. Determination of the parameter $f_{\max }=2 \cdot \varepsilon_{\mathrm{fn}}=0.154$, construction of the calculated triangular curve of frost heaving intensity (Fig. 5.) and determination of $\operatorname{tg} \beta$. $\operatorname{tg} \beta=0.154 / 207=0.744 \cdot 10^{-3}$.

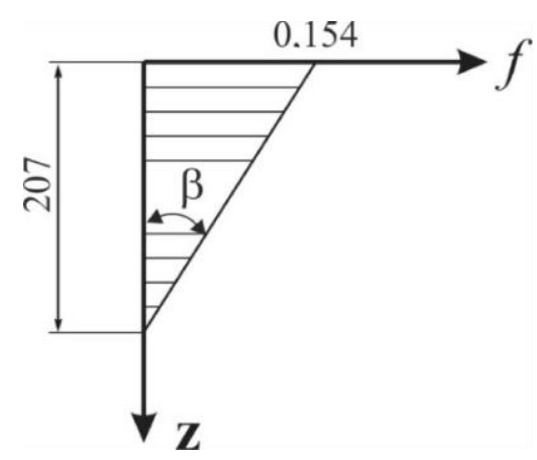

Fig. 5. The calculated curve of frost heaving intensity.

2. Determination of the acceptable freezing height of lower layers of subgrade $\left(\mathrm{Z}_{\mathrm{pr}}\right)$ from the expression:

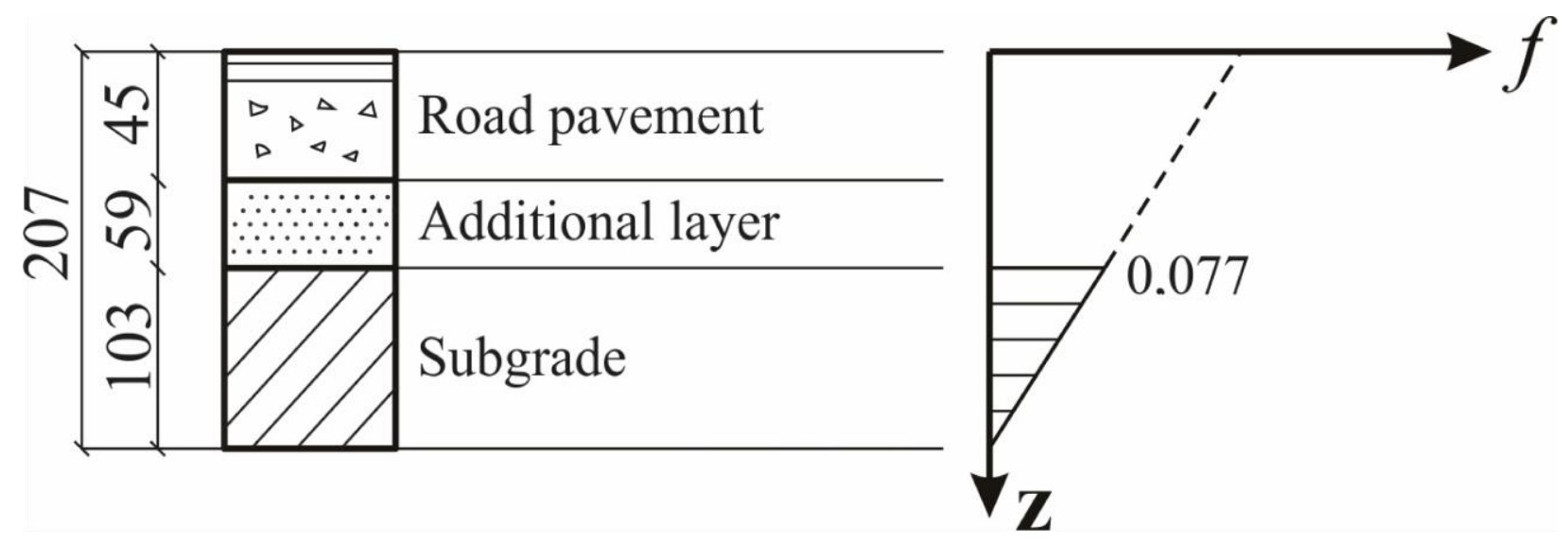

Fig. 6. The calculated scheme of the road structure.

3. Determination of the thickness of the frost protection layer $\left(Z_{\mathrm{fp}}\right)$ made of non-heaving material: $\mathrm{Z}_{\mathrm{fp}}=\mathrm{Z}_{\mathrm{pen}}$ $Z_{\text {pen(rp) }}-Z_{\mathrm{rp}}, Z_{\mathrm{fp}}=207-45-103=59 \mathrm{~cm}$.

In accordance with the performed calculation, the scheme of the road structure and the curve of frost heaving intensity are shown in Fig. 6.

The road structure for the heaving-prone sections should be made of stable non-heaving materials to the whole freezing depth.

The performed consideration allow us to make the following conclusions:

1. For a triangular curve of frost heaving intensity, the main part of frost heaving deformation is caused by freezing of the upper layers of soil. In road construction, this section is made of non-heaving materials. When subgrade is freezing, the deformation of frost heaving is much less. For the considered example, when the soil mass freezing occurs to the full depth $\left(Z_{\text {pen }}=207 \mathrm{~cm}\right)$, the total deformation of frost heaving will be more than 15 $\mathrm{cm}$. For the same example when subgrade is freezed in 
the road construction $\left(Z_{\mathrm{pen}}=103 \mathrm{~cm}\right)$, this deformation will be $4 \mathrm{~cm}$.

2. The proposed method is based on data from long-term field studies, which allows us to recommend it for use in engineering practice.

\section{References}

[1] Industry Road Codes ODN 218.046-01, Designing of non-rigid pavement, Introduced 20.12.2000, Moscow: Informavtodor, 144 (2001).

[2] The Russian State Standard GOST 28622-2012, Soils. Laboratory method for determining the degree of heaving, Introduced 18.12.2012, Moscow: Standartinform, 9 (2013).

[3] V.O. Orlov, Yu.D. Dubnov, N.D. Merenkov, Heaving of freezing soils and its influence on the foundations of structures: textbook, Leningrad: Stroyizdat (Leningrad Branch), 184 (1977).

[4] V.S. Sazhin, V.Ya. Shishkin, A.S. Volokh, Design and construction of structures foundations on heaving soils, Saratov: Saratov University Publishing House, 235 (1988). 